and standards of postgraduate training and methods of accrediting schemes are already well developed in the College. We need to concentrate on improving the translation of these policies into high quality psychiatric training throughout the country. The other vitally important factor in ensuring the College's compliance with the requirements of the CMO's Report, particularly with regard to the length of training, is the funding of the latest allocation of senior registrar posts. This will allow us to address our own bottleneck which occurs between registrar and senior registrar grades and fill the large numbers of vacant consultant posts in some areas. This is in contrast to the excess of senior registrars to consultants in many other specialities.

On behalf of the CTC I would also like to correct the impression which may have been gained from Dr Kisely's article that we have not been active or responsive to the issues raised by Calman. The statement that the CTC recommends only minimal changes to the present system is true in as much as we only see a need for continuing the progress made in psychiatry over recent years. This view is not intended to apply to the other Royal colleges where more radical changes may be needed. The CTC is an integral part of the Royal College of Psychiatrists and as such has been working to ensure that the standards of psychiatric training are high and continue to improve, since our foundation in 1979. We do not feel that radical change is necessary and are proud of the College's record of setting standards for training and involvement of trainees at all levels. As far as comments about reducing the length of postgraduate training to five or six years, we do not find a great deal of support for this among trainees themselves, as long as the time is spent in useful postgraduate training and not repeating previous experience while waiting for an SR (or to a lesser extent registrar) post. There is so much material in the psychiatric curriculum that trainees feel the need to expand the length of time spent in educational activities during the current training period.

The future for psychiatric training is to build on the progress made and to address the shortage of posts at SR level to allow a smoother transition through the training grades. We do not need radical changes, designed to address the problems of other specialities, imposed on us again. Trainees can be assured that the CTC will continue to be vociferous in its support of trainees and training standards within the College.

STEFfan Davies, Chair, Collegiate Trainees Committee (CTC), The Royal College of Psychiatrists

Sir: I am sorry that Dr Steffan Davies, Chairman of the Collegiate Training Committee (CTC), should take such exception to the suggestion that his committee should carefully consider whether psychiatric training could be further improved in the light of the Calman Report (Kisely, 1993).

I am well aware of the views of the CTC, given that I was one of the representatives on the committee for North Western Region until six months ago. Unless the committee has changed radically since, I found that many representatives were more open-minded about possible changes to training following Calman. In my experience, trainees in general certainly are. While training in psychiatry has many advantages over many other specialties, this does not mean that there is no room for improvement. Psychiatric trainees may wonder why training to be a psychiatrist in the UK should take so long; the Colleges of other medical specialities in Britain may soon require only five to six years of training, while the Royal Australian and New Zealand College of Psychiatrists stipulate only five years. Is the answer to an expanding psychiatric curriculum simply to increase the time spent in education activities within the current framework, or to critically examine the relevance of some of the training?

KISELY, S.R. (1993) The future of psychiatric training after the Calman report: a trainee's perspective. Psychiatric Bulletin, 17, 610-612.

STEVE KISELY, Northampton Health Authority, Department of Public Health Medicine, District Headquarters, Cliftonville Road. Northampton NN1 5DN

\section{CT scans in the elderly}

Sir: We read with interest the article by Jon Spear (Psychiatric Bulletin, 1993, 17, 536-537) which compares the quality of the use of computerised tomography (CT) scans in two psychogeriatric services. The author does not define the term 'quality' and it is assumed that this is measured in terms of identifying potentially treatable structural lesions (PTLs).

If diagnosing these PTLs is the only aim, as seems implied, then there is evidence supporting the finding that the most useful predictor is the presence on examination of focal neurological signs although further clinical prediction rules for the use of CT scans in the elderly are required (Martin et al, 1987; Wasson et al, 1985; Deitch, 1983).

In Spears study, patients of Service X, which only had access to CT scans through neurosurgical referral, suffered proportionately more 'risk factors' and had a greater rate of PTLs diagnosed. This implies that the application of neurosurgical criteria leads to more efficient use of CT scans. Discovering PTLs is obviously important but psychogeriatricians need to adopt 